\title{
KONFIGURASI SALURAN AKAR GIGI PADA GIGI MOLAR SATU MANDIBULA PERMANEN
}

\author{
(ROOT CANAL CONFIGURATION OF PERMANENT MANDIBULAR \\ FIRST MOLARS)
}

\author{
Yendriwati, Melissa \\ Department of Oral Biology \\ Faculty of Dentistry University of Sumatera Utara \\ Jl. Alumni No.2 Kampus USU Medan 2015
}

\begin{abstract}
Permanent mandibular first molar (PMFM) is the most frequently involved tooth in endodontic therapy, but it also has the highest treatment failure rate that leads to retreatment. One of the causes of unsuccessful treatment is the existence of untreated canal due to clinicians' failure in detecting the root canals. PMFM has a complex canal morphology. The purpose of this study was to investigate variations of the canal configuration of PMFM based on the Vertucci classification in several populations in Medan. This cross-sectional study used twenty five extracted PMFMs. Samples were subjected to clearing and canal staining technique and were examined using stereomicroscope. The results showed that variations of canal configuration in mesial roots were $36 \%$ of type II, $36 \%$ of type IV, $16 \%$ of type I, $8 \%$ of type III and $4 \%$ of type $\mathrm{V}$, meanwhile in distal roots were $84 \%$ of type I, $8 \%$ of type V, $4 \%$ of type II and $4 \%$ of type III. For PMFMs with three roots, all distolingual roots (100\%) had type I configuration. Based on this study, it can be concluded that MFMs have type I, II, III, IV and V canal configuration in mesial roots, type I, II, III and V in distal roots, type I in distolingual roots, whereas type VI, VII and VIII were not found in any roots.
\end{abstract}

Key words: canal configuration, permanent mandibular first molar

\begin{abstract}
Abstrak
Gigi molar satu (M1) mandibula permanen merupakan gigi yang paling sering mendapatkan perawatan endodonti, namun juga paling sering mengalami kegagalan perawatan dan membutuhkan perawatan ulang. Salah satu penyebab kegagalan ini adalah adanya saluran akar yang tidak terawat akibat kegagalan klinisi dalam mendeteksi saluran tersebut. M1 mandibula memiliki morfologi saluran akar yang sangat kompleks. Tujuan penelitian ini adalah untuk mengetahui variasi konfigurasi saluran akar gigi M1 mandibula berdasarkan klasifikasi Vertucci pada populasi di Medan. Studi cross sectional ini menggunakan 25 gigi M1 mandibula. Pada sampel dilakukan proses dekalsifikasi dan pewarnaan saluran akar, kemudian saluran akar diamati menggunakan stereomikroskop. Hasil penelitian menunjukkan variasi konfigurasi saluran akar pada akar mesial adalah 36\% tipe II, 36\% tipe IV, 16\% tipe I, $8 \%$ tipe III, dan $4 \%$ tipe V, sedangkan pada akar distal adalah $84 \%$ tipe I, $8 \%$ tipe V, 4\% tipe II dan 4\% tipe III. Pada gigi M1 mandibula yang memiliki tiga akar, akar distolingual seluruhnya (100\%) memiliki konfigurasi tipe I. Dapat disimpulkan bahwa gigi M1 mandibula memiliki konfigurasi saluran akar pada akar mesial tipe I, II, III, IV dan V, pada akar distal tipe I, II, III, dan V, pada akar distolingual seluruhnya tipe I, dan tidak dijumpai konfigurasi tipe VI, VII dan VIII pada seluruh akar.
\end{abstract}

Kata kunci: konfigurasi saluran akar, molar satu mandibula permanen

\section{PENDAHULUAN}

Gigi molar satu (M1) mandibula adalah gigi permanen pertama yang erupsi sekitar usia 6 tahun. ${ }^{1,2}$ Anatomi gigi berupa pit dan fisur pada permukaan oklusal menyebabkan gigi rentan terhadap karies ka- rena sisa makanan mudah menumpuk di daerah tersebut, terutama pit dan fisur yang dalam. ${ }^{3}$ Kurangnya pemahaman serta anggapan yang keliru orang tua bahwa gigi ini masih akan diganti menyebabkan mereka lalai untuk merawatnya. ${ }^{2}$ Gigi ini merupakan gigi yang paling kuat dalam lengkungnya dan 
berfungsi dalam mastikasi, mempertahankan vertikal dimensi dan kontinuitas lengkung rahang. ${ }^{4}$ Hal ini menyebabkan gigi ini penting untuk dipertahankan, salah satunya yaitu dengan melakukan perawatan saluran akar. ${ }^{1,5,6}$ Penelitian Ahmed dkk. pada tahun 2005 di Pakistan mengenai frekuensi dan distribusi gigi yang telah mendapat perawatan endodonti menunjukkan bahwa gigi M1 mandibula merupakan gigi yang paling sering mendapatkan perawatan endodonti dengan karies sebagai etiologi utamanya. ${ }^{1}$

Perawatan saluran akar atau endodonti adalah prosedur perawatan kimia dan mekanis yang dapat diterima secara biologis pada saluran akar untuk mengeliminasi penyakit pulpa dan periradikular serta untuk meningkatkan penyembuhan dan perbaikan jaringan radikular. ${ }^{7}$ Secara perspektif biomekanikal, perawatan endodonti meliputi pembersihan, pembentukan dan desinfeksi yang memungkinkan pengisian saluran akar dengan baik.

Gigi molar mandibula merupakan gigi yang paling sering mengalami kegagalan perawatan endodonti dan membutuhkan perawatan ulang. ${ }^{9}$ Salah satu penyebab kegagalan perawatan saluran akar adalah pembuangan jaringan pulpa dan mikroorganisme dari saluran akar yang tidak adekuat. ${ }^{5}$ Penelitian Khan dkk. di Peshawar pada 75 kasus perawatan endodonti yang mengalami kegagalan menunjukkan bahwa $40 \%$ penyebab kegagalan adalah adanya pengisian saluran akar yang kurang baik. ${ }^{9} \mathrm{Hal}$ ini dapat disebabkan oleh kegagalan klinisi dalam mendeteksi saluran akar tersebut. ${ }^{10,11}$ Oleh karena itu, pengetahuan tentang morfologi akar dan saluran akar merupakan persyaratan penting untuk menunjang keberhasilan perawatan saluran akar. ${ }^{6,10-13}$

Gigi M1 mandibula permanen memiliki morfologi akar dan saluran akar yang paling kompleks diantara gigi mandibula. ${ }^{14}$ Berbagai variasi morfologi internal dan eksternal akar dapat dijumpai pada gigi ini. Hal ini ditunjukkan dengan variasi jumlah akar dan saluran akar serta konfigurasinya. Variasi ini dipengaruhi oleh faktor genetik dan lingkungan. ${ }^{5}$

Penelitian ini bertujuan untuk mengetahui variasi konfigurasi saluran akar gigi M1 mandibula permanen berdasarkan klasifikasi Vertucci.

\section{BAHAN DAN METODE}

Penelitian ini merupakan penelitian deskriptif dengan rancangan cross sectional. Populasi dalam penelitian ini adalah gigi M1 mandibula permanen yang telah diekstraksi dan diperoleh dari beberapa tempat prakter dokter gigi dan puskesmas di Medan. Sampel penelitian berjumlah 25 gigi. Sampel dipilih berdasarkan kriteria inklusi akar sudah terbentuk sempurna dan kriteria eksklusi gigi pasca perawatan endodonti, karies mencapai pulpa, telah direstorasi crown dan onlay, resorbsi akar eksternal, fraktur akar, akar dilaserasi dan gigi dengan atrisi parah.

Sampel dibersihkan dari kalkulus dan sisa jaringan lunak menggunakan scaller elektrik, kemudian direndam dalam larutan natrium hipoklorit 5,25\%. Pembukaan akses dilakukan menggunakan bur bulat dan bur fisur seperti halnya pembukaan akses untuk perawatan endodonti. Jaringan pulpa dibuang menggunakan barbed broach nomor 15, lalu sampel direndam dalam larutan natrium hipoklorit 5,25\% selama 24 jam untuk melarutkan sisa jaringan pulpa dan debris yang terdapat dalam saluran akar. Kemudian sampel dicuci dengan air mengalir selama 2 jam. Sampel didekalsifikasi dengan direndam dalam larutan asam nitrat $5 \%$ selama 4 hari. Setiap 24 jam larutan asam nitrat diganti dengan larutan yang baru. Sampel kemudian dicuci dengan air mengalir selama 4 jam dan dikeringkan. Dehidrasi dilakukan dengan merendam sampel dalam alkohol 70\%, 96\% dan absolut masing-masing selama 12 jam. Selanjutnya sampel direndam dalam larutan metil salisilat selama 2 jam untuk menaikkan indeks refraktif gigi sehingga gigi menjadi transparan. Tinta diteteskan dari kamar pulpa hingga mewarnai seluruh saluran akar. Tinta yang berlebihan pada permukaan akar dibersihkan menggunakan kasa yang telah direndam dalam alkohol absolut. Pengamatan dilakukan menggunakan stereomikroskop dan tipe konfigurasi ditentukan berdasarkan klasifiksi Vertucci (Gambar 1).

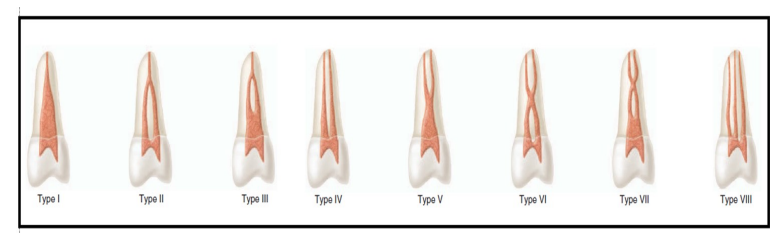

Gambar 1. Tipe konfigurasi saluran akar berdasarkan klasifikasi Vertuci

\section{HASIL}

Pada Tabel 1 terlihat persentase persentase tipe konfigurasi saluran akar berdasarkan klasifikasi Vertucci (Gambar 2) yang ditemukan dalam penelitian ini. Pada akar mesial dijumpai 16\% tipe I, 36\% tipe II, $8 \%$ tipe III, $36 \%$ tipe IV dan $4 \%$ tipe V. Pada akar distal dijumpai $84 \%$ tipe I, $4 \%$ tipe II, $4 \%$ tipe III dan $8 \%$ tipe V. Pada sampel yang memiliki tiga akar, akar distolingual seluruhnya memiliki konfigurasi tipe I 
Tabel 1. Distribusi frekuensi dan persentase tipe kon-figurasi saluran akar gigi molar satu mandibula permanen berdasarkan klasifikasi Vertucci

\begin{tabular}{lcccccccccc}
\hline & \multicolumn{7}{c}{ Tipe konfigurasi saluran akar pada akar mesial berdasarkan klasifikasi vertucci } \\
\cline { 2 - 7 } $\begin{array}{l}\text { Akar } \\
\text { (Jumlah Akar) }\end{array}$ & Tipe I & Tipe II & Tipe III & Tipe IV & Tipe V & Tipe VI & Tipe VII & Tipe VIII & Total \\
& 1 & $2-1$ & $1-2-1$ & 2 & $1-2$ & $2-1-2$ & $1-2-1-2$ & 3 & $(\%)$ \\
$(\%)$ & $(\%)$ & $(\%)$ & $(\%)$ & $(\%)$ & $(\%)$ & $(\%)$ & $(\%)$ & $(\%)$ \\
\hline \multirow{2}{*}{ Mesial (25) } & 4 & 9 & 2 & 9 & 1 & 0 & 0 & 0 & 25 \\
& $(16)$ & $(36)$ & $(8)$ & $(36)$ & $(4)$ & $(0)$ & $(0)$ & $(0)$ & $(100)$ \\
Distal (25) & 21 & 1 & 1 & 0 & 2 & 0 & 0 & 0 & 25 & $(100)$ \\
& $(84)$ & $(4)$ & $(4)$ & $(0)$ & $(8)$ & $(0)$ & $(0)$ & $(0)$ & 0 & 2 \\
Distolingual (2) & 2 & 0 & 0 & 0 & 0 & 0 & 0 & 0 & $(100)$ \\
\hline
\end{tabular}

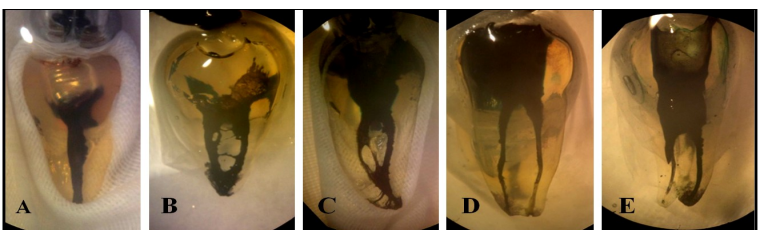

Gambar 2. Sampel dengan konfigurasi tipe I (A), tipe II (B), tipe III (C), tipe IV (D), tipe V (E) berdasarkan klasifikasi Vertucci

\section{PEMBAHASAN}

Pada penelitian ini, tipe konfigurasi saluran akar pada akar mesial berdasarkan klasifikasi Vertucci dengan frekuensi tertinggi adalah tipe II dan tipe IV (36\% pada masing-masing tipe), diikuti oleh tipe I (16\%), tipe III (8\%), dan tipe V (4\%). Penelitian yang dilakukan oleh Miloglu dkk. di Turki pada 533 gambar CBCT gigi M1 mandibula menemukan bahwa pada akar mesial, tipe IV merupakan tipe konfigurasi tertinggi (59,5\%), diikuti oleh tipe II $(32,8 \%)$, tipe V $(2,4 \%)$, tipe III $(2,3 \%)$, tipe VIII $(1,3 \%)$, tipe I $(0,4 \%)$ dan VI $(0,4 \%) .{ }^{14}$ Penelitian yang dilakukan oleh Chourasia, dkk. di India pada 150 gigi M1 mandibula permanen menemukan bahwa tipe konfigurasi saluran akar pada akar mesial dengan frekuensi tertinggi adalah tipe IV (54\%), diikuti oleh tipe II $(36,6 \%)$, tipe VI $(8 \%)$ dan tipe $\mathrm{V}(0,6 \%) .{ }^{5} \mathrm{Pe}-$ nelitian Ahmed HA, dkk. di Sudan pada 100 gigi M1 mandibula permanen menemukan bahwa tipe konfigurasi saluran akar pada akar mesial dengan frekuensi tertinggi adalah tipe IV (73\%), kemudian tipe II (14\%), tipe I (3\%), tipe VIII (2\%), tipe III (1\%), tipe V $(1 \%)$, dan tipe VII $(1 \%) .{ }^{15}$ Hasil penelitian ini sesuai dengan penelitian Miloglu, Chourasia dan Ahmed, yang tipe konfigurasi saluran akar pada akar mesial dengan frekuensi tertinggi adalah tipe IV dan II.

Tipe konfigurasi saluran akar pada akar distal berdasarkan klasifikasi Vertucci dengan frekuensi tertinggi adalah tipe I (84\%), diikuti oleh tipe V $(8 \%)$, kemudian tipe II dan tipe III (masing- masing 4\%). Penelitian Miloglu, dkk. menemukan bahwa tipe I merupakan tipe konfigurasi tertinggi $(74,7 \%)$ pada akar distal, diikuti oleh tipe II $(12,3 \%)$, tipe IV $(9,7 \%)$, tipe V $(1,8 \%)$, dan tipe III $(1,5 \%){ }^{14} \mathrm{Pe}-$ nelitian Chourasia, dkk. menemukan bahwa tipe konfigurasi saluran akar dengan frekuensi tertinggi pada akar distal adalah tipe I $(65,3 \%)$, diikuti oleh tipe II $(20,6 \%)$, tipe IV $(9,3 \%)$, tipe V( $3,3 \%)$ dan tipe III $(1,3 \%){ }^{5}$ Penelitian Ahmed HA, dkk. Menemukan bahwa tipe konfigurasi saluran akar pada akar distal dengan frekuensi tertinggi adalah tipe I (38\%), kemudian tipe II (28\%), tipe IV (22\%), tipe VI $(6 \%)$, tipe VIII $(3 \%)$, dan tipe V $(1 \%) .{ }^{15}$ Hasil penelitian ini sesuai dengan tiga penelitian yang telah dipaparkan di atas, yang tipe konfigurasi saluran akar pada akar distal yang paling banyak dijumpai adalah tipe I, sedangkan tipe lainnya bervariasi. Morfologi eksternal akar distal lebih membulat dibanding akar mesial sehingga kecil kemungkinannya untuk mengakomodasi dua saluran akar yang terpisah. $^{5}$

Pada gigi M1 mandibula permanen yang memiliki tiga akar, seluruhnya memiliki konfigurasi tipe I berdasarkan klasifikasi Vertucci. Hal ini sesuai dengan penelitian Chourasia, dkk. dan Miloglu, dkk. yang keduanya mendapatkan bahwa pada akar distolingual, seluruhnya memiliki konfigurasi Tipe I., ${ }^{5,14}$

Pada penelitian ini tidak ditemukan konfigurasi tipe IV, VI, VII dan VIII seperti yang ditemukan pada penelitian lainnya. Hal ini dapat disebabkan oleh jumlah sampel yang kurang dan juga kurang tersedianya sampel yang memenuhi kriteria inklusi dan eksklusi sehingga tidak semua tipe konfigurasi dapat diperoleh.

Teknik dekalsifikasi dan pewarnaan saluran akar merupakan metode gold standard dalam mempelajari anatomi saluran akar. ${ }^{16}$ Tidak seperti gambar radiografi, teknik ini dapat memberikan tampilan tiga dimensi rongga pulpa sehingga memungkinkan untuk memberikan tampilan detil, akurat dan menyeluruh dari ruang pulpa dan saluran akar.${ }^{15-17}$ Teknik ini tidak memerlukan preparasi ke dalam saluran menggunakan instrumen sehingga bentuk dan hubungan saluran akar dapat terjaga. Teknik ini juga 
sederhana dan tidak mahal untuk pemeriksaan sistem saluran akar in vitro. ${ }^{18}$

Berdasarkan penelitian ini dapat disimpulkan bahwa gigi M1 mandibula memiliki konfigurasi saluran akar pada akar mesial tipe I, II, III, IV dan V, pada akar distal tipe I, II, III, dan V, pada akar distolingual seluruhnya tipe I, tidak dijumpai konfigurasi tipe VI, VII dan VIII pada seluruh akar.

\section{Daftar Pustaka}

1. Ahmed H, Sadaf D, Rahman M. Frequency and distribution of endodontically treated teeth. JCPSP 2009; 19: 605-8.

2. Harshanur IW. Anatomi Gigi. Jakarta: EGC, 2012: 213-4.

3. Pintauli S, Hamada T. Menuju gigi dan mulut sehat: pencegahan dan pemeliharaan. Medan: USU Press, 2014: 5-6.

4. Scheid RC, Weiss G. Woelfel's dental anatomy. 8th ed. Philadelphia: Lippincott Williams \& Wilkins, 2002: 121.

5. Chourasia HR, Meshram GK, Warhadpande M, Dakshindas D. Root canal morphology of mandibular first permanent molars in an indian population. International J of Dentistry 2012.

6. Carotte P. Endodontics: part 4 morphology of the root canal system. British Dent J 2004; 197 (7): 379-83.

7. Chng HK, Chen NN, Koh ET, Lam EC, Lim KC, Sum CP. Guidlines for root canal treatment. SDJ 2004; 26: 60-2.

8. Pablo OV, Estevez R, Sanchez MP, Heilborn C, Cohenca N. Root anatomy and canal configuration of the permanent mandibular first molar: a systematic review. JOE 2010; 26 (12): 1919-31.

9. Khan M, Rehman K, Saleem M. Causes of endo- dontic treatment failure - a study. Pakistan Oral and Dental Journal 2010; 30: 232-6.

10. Hargreaves KM, Cohen S, Berman LH, eds. Cohen's pathway of the pulp. 10th ed. Missouri: Mosby Elsevier, 2011: 22-23, 136-44, 151-2, 457.

11. Vertucci FJ. Root canal morphology and its relationship to endodontic procedures. Endodontic topics 2005; 10: 3-29.

12. Ingle JI, Bakland LK, Baumgartner JC. Ingle's endodontics. 6th ed. Hamilton: BC Decker INC, 2008: 151-5, 202-5.

13. Tsujimoto Y. Forms of roots and root canals in endodontic therapy. J Oral Biosci 2009; 51 (4): 218-23.

14. Miloglu O, Arslan H, Barutcigil C, Cantekin K. Evaluating root and canal configuration of mandibular first molars with cone beam computed tomography in a turkish population. $\mathrm{J}$ of Dent Science 2012; 20:1-7.

15. Ahmed HA, Abu-bakr NH, Yahia NA, Ibrahim YE. Root and canal morphology of permanent mandibular molars in a sudanese population. Int Endodontic J 2007; 40: 766-71.

16. Neelakantan P, Subbarao C, Subbarao CV. Comparative evaluation of modified canal staining and clearing technique, cone beam computed tomography, peripheral quantitative computed tomography, spiral computed tomography, and plain and contrast medium-enhanced digital radiography in studying root canal morphology. JOE 2010; 36: 1547-51.

17. Javidi M, Vatanpour M, Shirazian S. Agreement between clinicians in determining the root canal system in radiographic images. IEJ 2006; 1 (4): 125-8.

18. Maralingannavar M, Desai R, Vanaki SS. Demonstration of root canal morphology of human permanent teeth using transparent teeth using transparent tooth model system. IJCD 2010; 1(3): 18-22. 